EASD

Procedia
EURODYN 2020

XI International Conference on Structural Dynamics M. Papadrakakis, M. Fragiadakis, C. Papadimitriou (eds.) Athens, Greece, 23-26 November 2020

\title{
NUMERICAL PERFORMANCE EVALUATION OF A BI-DIRECTIONAL ROLLER SEISMIC ISOLATION BEARINGS
}

\author{
Ricardo González ${ }^{1}$, Nelson Ortiz-Cano ${ }^{1}$, Andrés Nieto-Leal ${ }^{1}$ and Carlos \\ Gaviria-Mendoza ${ }^{1}$. \\ ${ }^{1}$ Department of Civil Engineering, Universidad Militar Nueva Granada, Cajicá, CU 250247, Colombia. \\ e-mail: ing.ricardo.gonzalez.olaya@gmail.com,nelson.ortiz@unimilitar.edu.co, \\ andres.nieto@unimilitar.edu.co, carlos.gaviria@unimilitar.edu.co
}

Keywords: Seismic isolation, Roller isolation systems, Bi-directional roller bearings.

\begin{abstract}
Base isolation systems (BISs) are devices that mitigate the harmful effects of earthquakes on structures. Nowadays, designers are implementing this technology to bridge and building special projects located in areas of high seismic risk to improve their performance under earthquake excitations. However, high cost, uncertainty and lack of knowledge in the design have limited its massive use, specially in developing countries. According to the mechanical behavior, BISs are clasiffied in elastomeric bearings, sliding bearings and roller bearings. In this work, the performance of a bi-directional roller bearings system was evaluated; thus, the main objective of this publication is to show the efficiency of a bi-directional roller bearing in improving the structural seismic response of multicolumn systems by means of reducing accelerations and displacements. A numerical code in Matlab was written to simulate the response of the structures under base excitations, the finite element method (FEM) in conjunction with frame elements was used to solve the governing equations. The validation of the numerical model was done by direct comparisons between experimental and numerical data.
\end{abstract}

ISSN:2311-9020 (C) 2020 The Authors. Published by EASD Procedia.

Peer-review under responsibility of the Organizing Committee of EURODYN 2020.

doi: $10.47964 / 1120.9114 .18500$ 


\section{INTRODUCTION}

Various seismic isolation systems have been developed to protect buildings and reduce the potentially harmful effects produced by earthquakes. Isolations systems are commonly grouped into three types: (1) elastomeric bearings, (2) sliding bearings and (3) roller bearings. Jangid and Datta [1], Naeim and Kelly [2], Kunde and Jangid [3] and Harvey and Kelly [4] presented a comprehensive review of the study and use of these systems over the past three decades.

Seismic isolation systems, regardless of their type, partially decouple the horizontal motion between the structure and its base by incorporating a flexible interface with low lateral stiffness at the foundation level. This flexible interface corresponds to the isolation devices or seismic isolators, which allow to avoid that the natural frequencies of the structure coincide with the predominant frequencies contained in the seismic excitation; thus, reducing acceleration and horizontal displacements of the structure $[1,5]$. Likewise, it is important to highlight that all types of seismic isolation systems have to return to their initial position, self-centering, after the excitation occurred; in addition, isolation systems should have the capacity of dissipate energy through different mechanisms, typical of each type of system.

Isolation systems have been successfully used since 1969 in 12.720 projects around the world [6]. New construction projects, the retrofitting of structures with insufficient resistance to withstand earthquakes and the updating of structures to current regulations are some examples in which this technology have been implemented [e.g. 2, 7-11]. Spencer Jr. and Nagarajaiah [12] attributed the success of seismic isolation to its reliability, stability, simplicity of design and low cost compared to other seismic protection techniques.

The main objective of this publication is to show the efficiency of a bi-directional roller bearings in improving the structural seismic response of multicolumn systems. This type of isolator was developed by Lee et al. [13] and it is composed of a cylindrical bearing system supported by an inclined V-shaped surface. Initially, this system was studied and implemented in bridges and subsequently studied by Ortiz-Cano et al. [14] to be used in multicolumn structural systems.

Following the work done by Ortiz-Cano et al. [14], in this work a numerical code in Matlab was written to simulate the response of the structures under base excitations, the finite element method (FEM) in conjunction with frame elements was used to solve both the governing equations and boundary conditions. The validation of the numerical model was done by direct comparisons between experimental and numerical data. Finally, a parametric study allowed to verify the efficiency of the isolation system in the control of vibrations under conditions of real earthquake records.

\section{MOTION EQUATIONS OF ISOLATED BUILDINGS WITH RB SYSTEM}

The equation of motion, in the time domain, that represents the dynamic bahavior of isolated buildings with RB systems under base excitations in a multiple degrees of freedom (MDoF) system is given in Eq.(1),

$$
M \ddot{u}+C \dot{u}+K u+R\left(f_{s}+f_{d r}+f_{d s}\right)=-M \Gamma \ddot{u}_{g}
$$

Where $M, C$ and $K$ are the mass, damping and stiffness matrices of the MDoF system, respectively. $\ddot{u}, \dot{u}$ and $u$ are the acceleration, velocity and displacement vectors. 
On the other side, in Eq.(1), $\ddot{u}_{g}$ is the seismic excitation vector that contains the base accelerations for each direction in which the building can be excited; i.e., 3 translational and 3 rotational DoF's in the Cartesian space. The term $\Gamma$ is an influence matrix that relates the excited DoF's $i$ with the direction of the seismic excitation $j$. The elements of the $\Gamma$ matrix take values of 0 or 1 according to the following expression:

$$
\Gamma_{i j}= \begin{cases}0 & \text { if the DoF } i \text { isn't excited in the direction } j \\ 1 & \text { if the DoF } i \text { is excited in the direction } j\end{cases}
$$

where, $R$ is a matrix that allocates the forces of restoration $f_{s}$, rolling friction $f_{d r}$ and sliding friction $f_{d s}$ developed by the RB system in $j$ direction into a matrix that contains the forces in the DoF's system in $i$ direction. The elements that make up the $R$ vector take values of 0 or 1 as follows.

$$
R_{i j}= \begin{cases}0 & \text { if in the DoF } i \text { the forces } f_{s}, f_{d r} \text { and } f_{d s} \text { aren't developed in the direction } j \\ 1 & \text { if in the DoF } i \text { the forces } f_{s}, f_{d r} \text { and } f_{d s} \text { are developed in the direction } j\end{cases}
$$

The forces $f_{s}, f_{d r}$ and $f_{d s}$, which characterize the RB system, are defined through Equation (4), (5), (6) and (7) as follows,

$$
\begin{aligned}
& f_{s}{ }^{\mathrm{T}}=\left\{\frac{1}{2} m_{1} g \sin \left(\theta_{1}\right) f_{H_{1}}(u) \quad \frac{1}{2} m_{2} g \sin \left(\theta_{2}\right) f_{H_{2}}(u)\right\} \\
& f_{d r}^{\mathrm{T}}=\left\{\mu_{r_{1}} m_{1} g f_{H_{1}}(\dot{u}) \quad \mu_{r_{2}} m_{2} g f_{H_{2}}(\dot{u})\right\} \\
& f_{d s}^{\mathrm{T}}=\left\{\mu_{s_{1}} N_{1} f_{H_{1}}(\dot{u}) \quad \mu_{s_{2}} N_{2} f_{H_{2}}(\dot{u})\right\} \\
& f_{H}(x)=\left\{\begin{array}{clc}
1 & \text { if } & x \geq d \\
\frac{1}{d} x & \text { if } & -d<x<d \\
-1 & \text { if } & x \leq d
\end{array}\right.
\end{aligned}
$$

where $m$ is the mass supported by the isolator, $g$ is the gravitational acceleration, $\mu_{r}$ is the rolling friction coefficient, $\mu_{s}$ is the sliding friction coefficient, $N$ is the normal force applied on the sliding interface, $\theta$ is the angle of the inclined $\mathrm{V}$-shape surfaces and $f_{H}$ is a function governed by a parameter called yield displacement $d$ and a variable auxiliary $x$ associated with the displacement and speed of the base of system (7). Additionally, the subscripts 1 and 2 denote the proper direction of each parameter in the horizontal plane.

In order to solve Eq.(1), the numerical solver of ordinary differential equations (ODE's) ode23t implemented by MATLAB was used; it showed greater efficiency and numerical stability compared to others methods offered by MATLAB ODE pack. In general, the algorithm of this solver is an implementation of the trapezoidal rule with an adaptive step-size associated with the use of a "free" interpolant [15]. The use of this solver requires that Eq. (1), which is a second order equation, be rewritten as a two first-order ODE system, as shown in the following expression:

$$
\dot{v}=A_{1} v(t)+A_{2} H(u, \dot{u})+A_{3} \ddot{u}_{g}
$$


with

$$
A_{1}=\left[\begin{array}{cc}
0 & \mathrm{I} \\
-M^{-1} K & -M^{-1} C
\end{array}\right] ; \quad A_{2}=\left[\begin{array}{c}
0 \\
-M^{-1} R
\end{array}\right] ; \quad A_{3}=\left[\begin{array}{c}
0 \\
-\Gamma
\end{array}\right]
$$

where, $A_{1}$ and $v(t)^{\mathrm{T}}\left(=\left\{\begin{array}{ll}u & \dot{u}\end{array}\right\}\right)$ represent the state matrix and state vector of the system. The non-linearity of the system is represented by $H(u, \dot{u})$ function, which includes the effects of the RB system previously described.

\section{VALIDATION OF THE NUMERICAL SIMULATION ROUTINE}

To validate the numerical simulation routine, the results of an experimental evaluation [14] and a numerical simulation of a building with and without RB isolation were compared.

The characteristics of the building model and the numerical simulations that validate the routine are presented in the next subsections.

\subsection{BUILDING MODEL}

\subsubsection{Description of the physical model}

The physical model consists of 4 storys supported by columns of polymeric material with rectangular section of $20.0 \times 2.9 \mathrm{~mm}$. The model has a total height of $803.4 \mathrm{~mm}$ and a rectangular plant with dimensions of $150 \times 200 \mathrm{~mm}$. The slabs that make up each story and the story-column connections are constructed of aluminum plates. The base of the building has a thickness of $8.0 \mathrm{~mm}$, storys and story-column connections a thickness of $4.0 \mathrm{~mm}$. On the other hand, the building supports superimposed masses of $0.50 \mathrm{~kg}$ on the second and third storys. A detailed outline of the geometry of the physical model is presented in Figure 1.

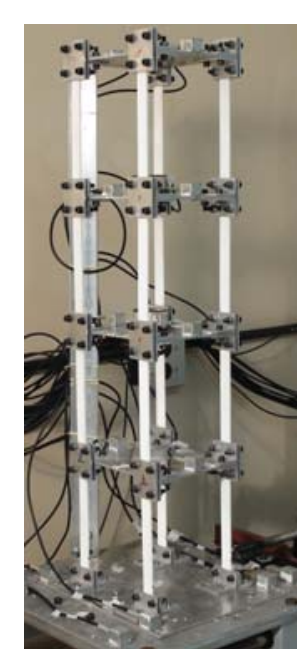

(a) Picture of physical model.

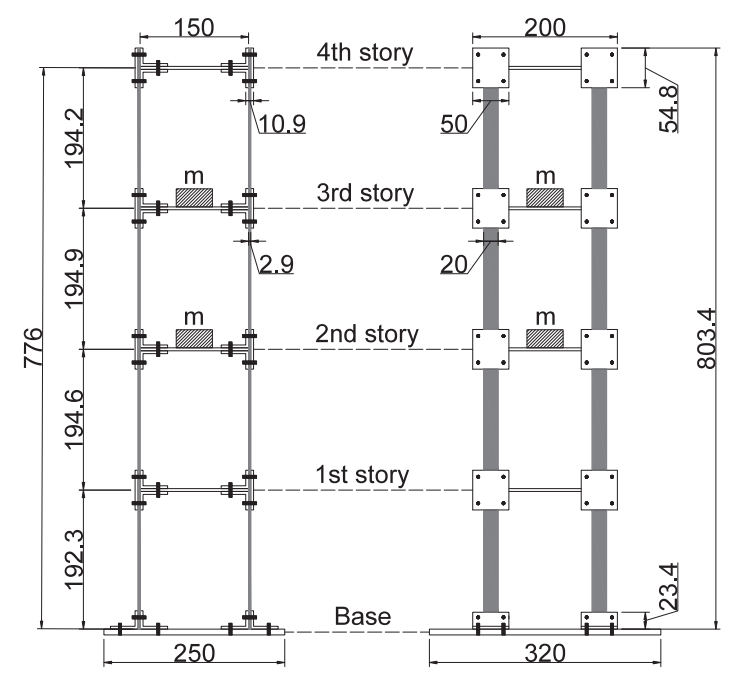

(b) Scheme of physical model, measures in $\mathrm{mm}$.

Figure 1: Physical model. 


\subsubsection{Modal parameters identified}

According to the experimental tests carried out and the analysis methodologies adopted by the author, the modal parameters identified for the fixed-base building model are summarized in Table 1.

\begin{tabular}{ccc}
\hline Mode & $f_{\text {exp }}(\mathrm{Hz})$ & $\xi_{\exp }(\%)$ \\
\hline $1^{\text {st }}$ flexural (weak direction) & $6.82 \pm 0.02$ & $0.59 \pm 0.03$ \\
$2^{\text {nd }}$ flexural (weak direction) & $20.44 \pm 0.03$ & $0.51 \pm 0.01$ \\
$1^{\text {st }}$ torsional & $21.55 \pm 0.02$ & $2.88 \pm 0.03$ \\
$3^{\text {rd }}$ flexural (weak direction) & $31.70 \pm 0.02$ & $0.30 \pm 0.01$ \\
$4^{\text {th }}$ flexural (weak direction) & $36.65 \pm 0.03$ & $0.34 \pm 0.02$ \\
$2^{\text {nd }}$ torsional & $77.44 \pm 0.02$ & $3.92 \pm 0.01$ \\
\hline
\end{tabular}

Table 1: Modal parameters identified in the building.

In addition, considering the Rayleigh damping, values of the damping constants $\alpha=4.03 \times$ $10^{-1}$ and $\beta=5.58 \times 10^{-5}$ were determined for the first two modes of vibration, which add up to $95 \%$ modal participation of the total mass of the building.

\subsection{NUMERICAL MODELING}

The structural system that makes up the physical model of the building was modelled using three-dimensional frame elements, 68 elements were defined with 56 nodes as presented in Figure 2.

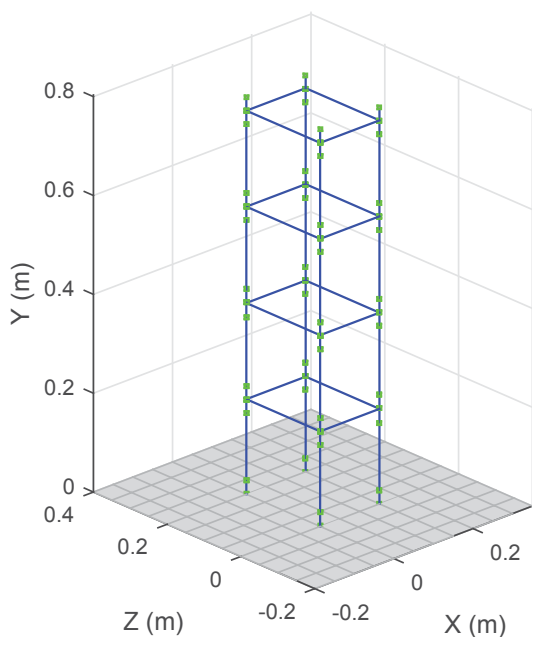

Figure 2: Numerical model raised.

In the numerical model, 3 types of frame elements were used, which are characterized by an elasticity modulus $E$, a Poisson ratio $\nu$ that defines the shear modulus $G$, a density $\rho$, a area $A$, a polar moment of inertia $J_{x}$ and a moments of inertia $I_{y}$ and $I_{z}$. Table 2 lists the characteristics of the elements used in the numerical representation of the physical model. 


\begin{tabular}{cccccccc}
\hline $\begin{array}{c}\text { Element } \\
\text { type }\end{array}$ & $\begin{array}{c}E \\
(\mathrm{GPa})\end{array}$ & $\nu$ & $\begin{array}{c}\rho \\
\left(\mathrm{Kg} / \mathrm{m}^{3}\right)\end{array}$ & $\begin{array}{c}A \\
\left(\mathrm{~m}^{2}\right)\end{array}$ & $\begin{array}{c}J_{x} \\
\left(\mathrm{~m}^{4}\right)\end{array}$ & $\begin{array}{c}I_{y} \\
\left(\mathrm{~m}^{4}\right)\end{array}$ & $\begin{array}{c}I_{z} \\
\left(\mathrm{~m}^{4}\right)\end{array}$ \\
\hline 1 & 28 & 0.325 & 1800 & $5.9 \times 10^{-5}$ & $1.5 \times 10^{-10}$ & $2.0 \times 10^{-9}$ & $4.1 \times 10^{-11}$ \\
2 & 70 & 0.331 & 2700 & $4.0 \times 10^{-4}$ & $7.7 \times 10^{-9}$ & $1.3 \times 10^{-7}$ & $2.5 \times 10^{-9}$ \\
3 & 70 & 0.331 & 0 & $4.0 \times 10^{-4}$ & $7.7 \times 10^{-9}$ & $1.3 \times 10^{-7}$ & $2.5 \times 10^{-9}$ \\
\hline
\end{tabular}

Table 2: Mechanical and geometric characteristics of the elements.

The elements type 1 represent the columns constructed in polymeric material, while the elements type 2 and 3 represent the aluminum connections and slabs defined as beams in the numerical model. It is important to highlight that the density of the elements type 3 takes the value of 0 because the slab masses, and other elements that provide mass on each story, were modelled as masses concentrated on the nodes of each story. In this way, concentrated masses of $539.3 \mathrm{~g}, 196.6 \mathrm{~g}, 321.2 \mathrm{~g}, 321.1 \mathrm{~g}$ and $196.6 \mathrm{~g}$ were incorporated into each of the nodes of the base, $1^{\text {st }}, 2^{\text {nd }}, 3^{\text {rd }}$ and $4^{\text {th }}$ story.

\subsubsection{Building with fixed base}

The validation of the numerical model corresponding to the fixed-base building was performed taking in to account both the domain of frequencies and the domain of time; in addition, the frequency response functions (FRFs) and the acceleration response of the model storys were used.

Firstly, the validation in the frequency domain was carried out by direct comparison between the natural frequencies and the FRFs obtained experimentally and numerically.

In Figure 3 the natural frequencies obtained numerically and the vibration modes associated with each frequency are presented, while Figures 4 and 5 show a comparison of the experimental and numerical FRFs of the structure. Accordingly, it is observed that the numerical vibration frequencies are in agreement with the experimental vibration frequencies with a relative difference less than $0.6 \%$ in the first four vibration modes (Fig. 3a, b, c, d).

Likewise, using the damping ratios presented in Table 1 the FRF's were computed and then compared with the experimental ones; there is an excellent correlation between experimental and numerical FRFs as shown in Figures 4 and 5. However, it is noteworthy that if the damping ratios given by Rayleigh damping model are used (instead of those obtained experimentally) there is a significant difference for high vibration modes. 


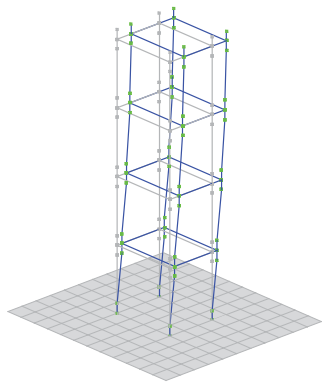

(a) $1^{\text {st }}$ mode, $6.83 \mathrm{~Hz}$.

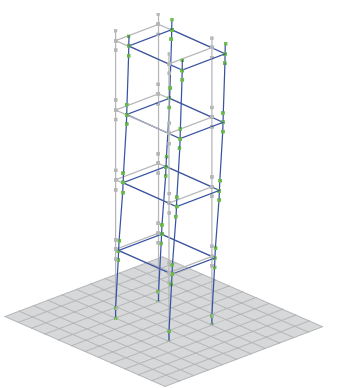

(d) $4^{\text {th }}$ mode, $29.92 \mathrm{~Hz}$.

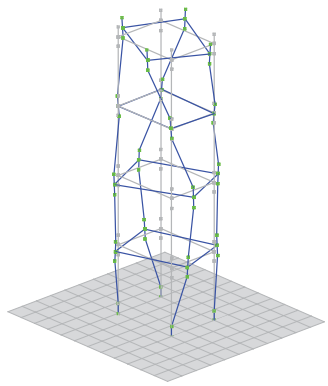

(g) $7^{\text {th }}$ mode, $67.97 \mathrm{~Hz}$.

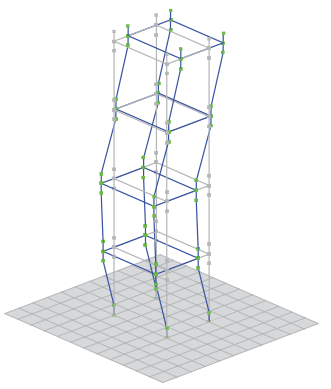

(b) $2^{\text {nd }}$ mode, $20.44 \mathrm{~Hz}$.

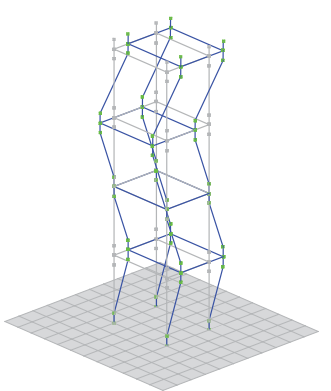

(e) $5^{\text {th }}$ mode, $31.55 \mathrm{~Hz}$.

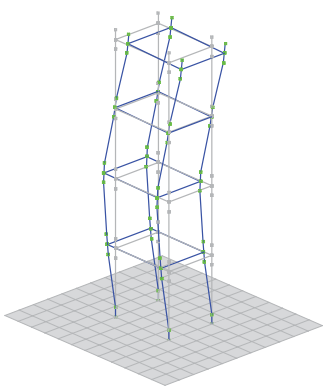

(h) $8^{\text {th }}$ mode, $97.49 \mathrm{~Hz}$.

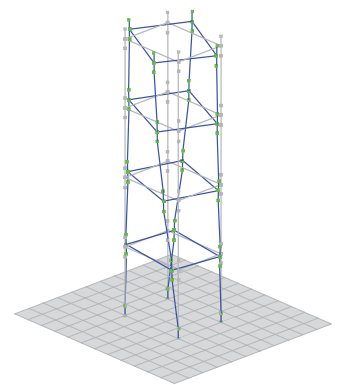

(c) $3^{\text {rd }}$ mode, $21.55 \mathrm{~Hz}$.

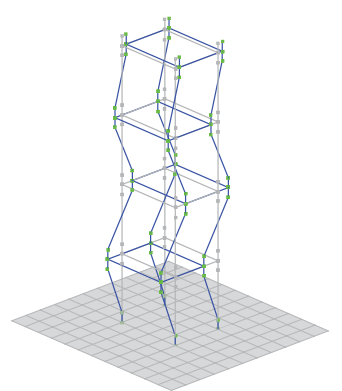

(f) $6^{\text {th }}$ mode, $36.86 \mathrm{~Hz}$.

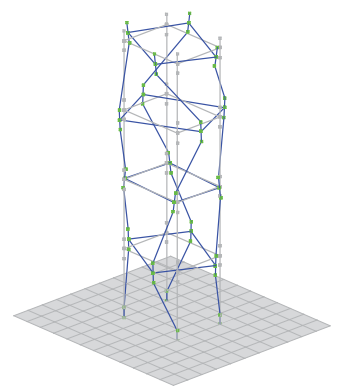

(i) $9^{\text {th }}$ mode, $116.10 \mathrm{~Hz}$.

Figure 3: Vibration modes and vibration frequencies.

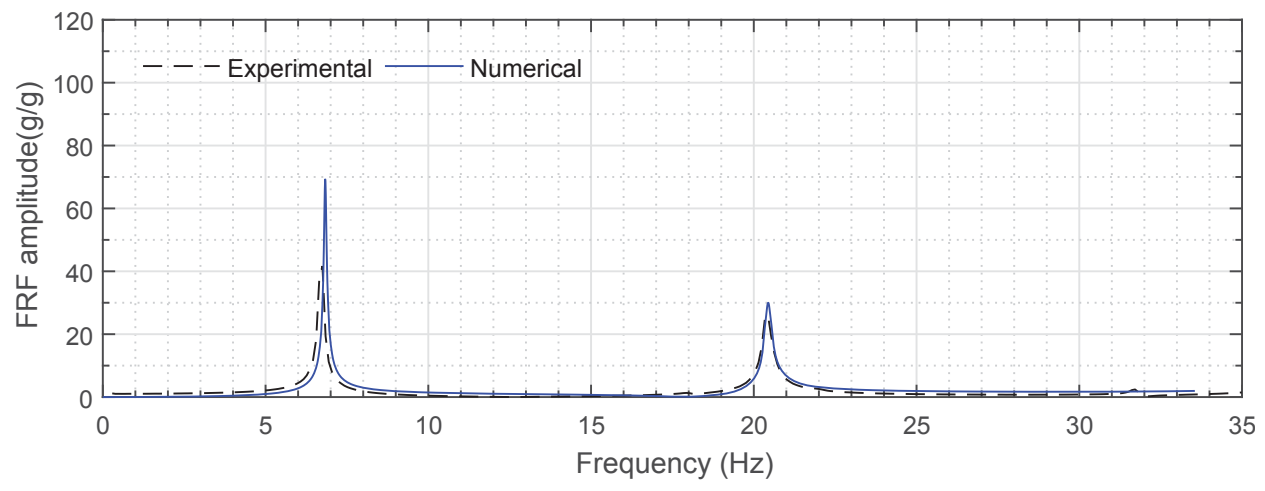

Figure 4: FRFs comparison of the $2^{\text {nd }}$ story with base excitation. 


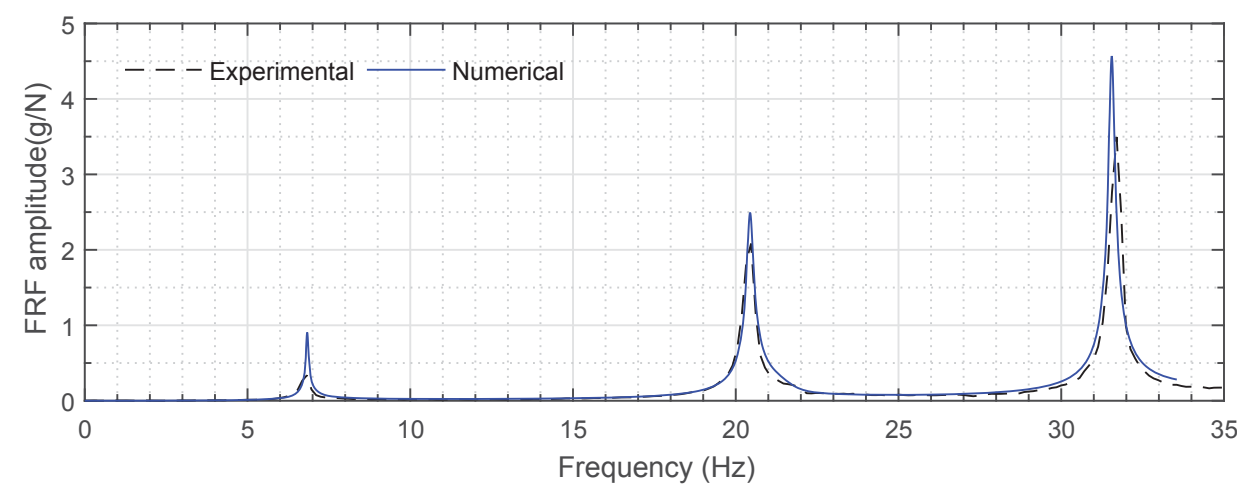

Figure 5: FRFs comparison of the $4^{\text {th }}$ story with impact excitation in the $1^{\text {st }}$ story.

Secondly, in the time domain, the validation of the numerical model was carried out by comparing the numerical and experimental response of the structure when subjected to random base excitation. The comparison of the responses is shown in Figure 6, it is evident that the numerical model represent the response of the fixed-base building.

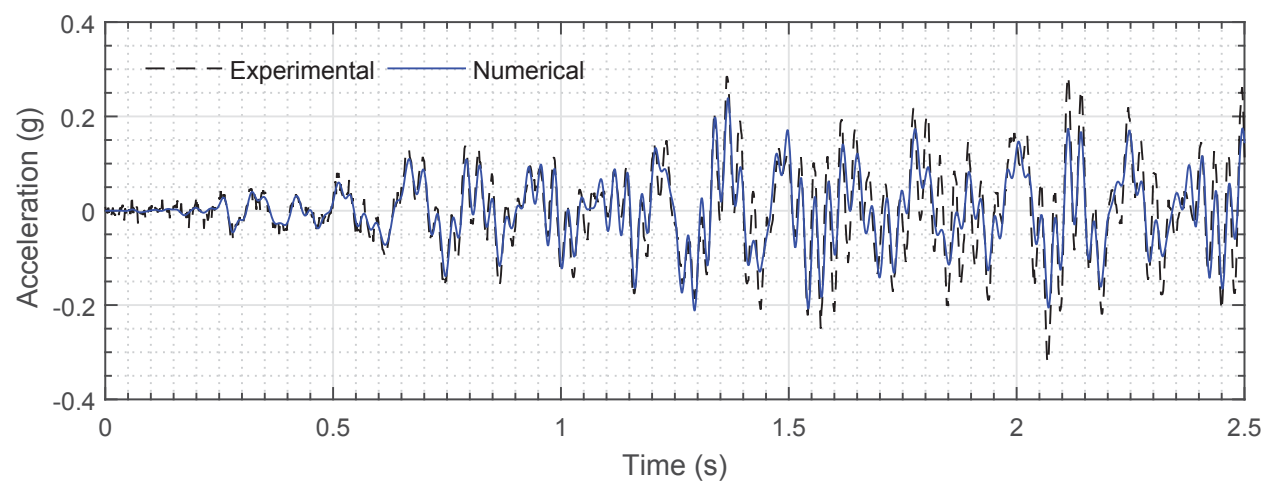

Figure 6: Time series of acceleration response of the $3^{\text {rd }}$ story.

\subsubsection{Building with RB system}

Turning the attention to the use of roller bearings, the numerical model representing the building with RB was validated by comparing the numerical and experimental response of the structure in both free vibration and base excitation conditions.

To model the building $+\mathrm{RB}$ system, the characteristics of the fixed base structure and the $\mathrm{RB}$ system parameters $\mu_{r}=0.0054, d=1.2 \times 10^{-3} \mathrm{~m}$ and $\theta=5^{\circ}$ were used. In the free vibration simulations the initial lateral displacement condition $u_{0}=0.025 \mathrm{~m}$ and initial velocity $\dot{u}_{0}=0 \mathrm{~m} / \mathrm{s}$ were considered, while in the simulations of the building $+\mathrm{RB}$ under base excitation initial conditions $u_{0}=0 \mathrm{~m}$ and $\dot{u}_{0}=0 \mathrm{~m} / \mathrm{s}$ were considered in conjunction with a random base excitation record that contained predominant frequencies between 0 and $6 \mathrm{~Hz}$.

In Figures 7 and 8 are shown the comparisons between numerical simulations and experimental responses of the building $+\mathrm{RB}$ system in both conditions free vibration and base excitation. In both figures certain degree of dispersion between the responses is noticeable; this dispersion could be related to deficiencies in the isolation system since it is not possible to completely restrict motion in the different directions in which the RB system operates Ortiz-Cano 
et al. [14]. However, despite some dispersion, there is a very good agreement between the measured and numerically responses, which prove that the numerical model is able to adequately represent the dynamic behavior of a building $+\mathrm{RB}$ system.

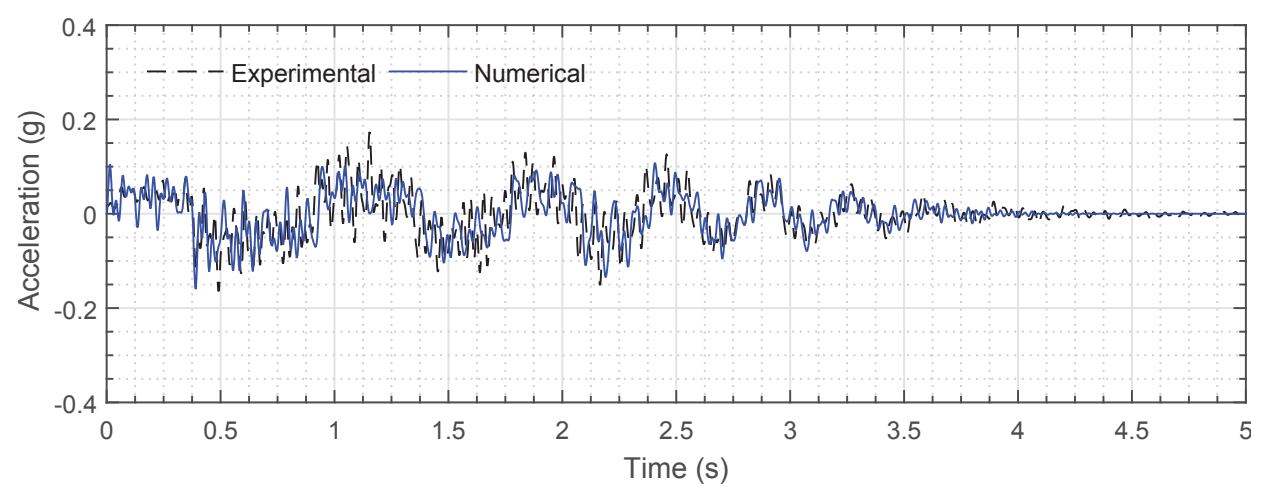

Figure 7: Time series of acceleration response of the $1^{\text {st }}$ story with RB in free vibration.

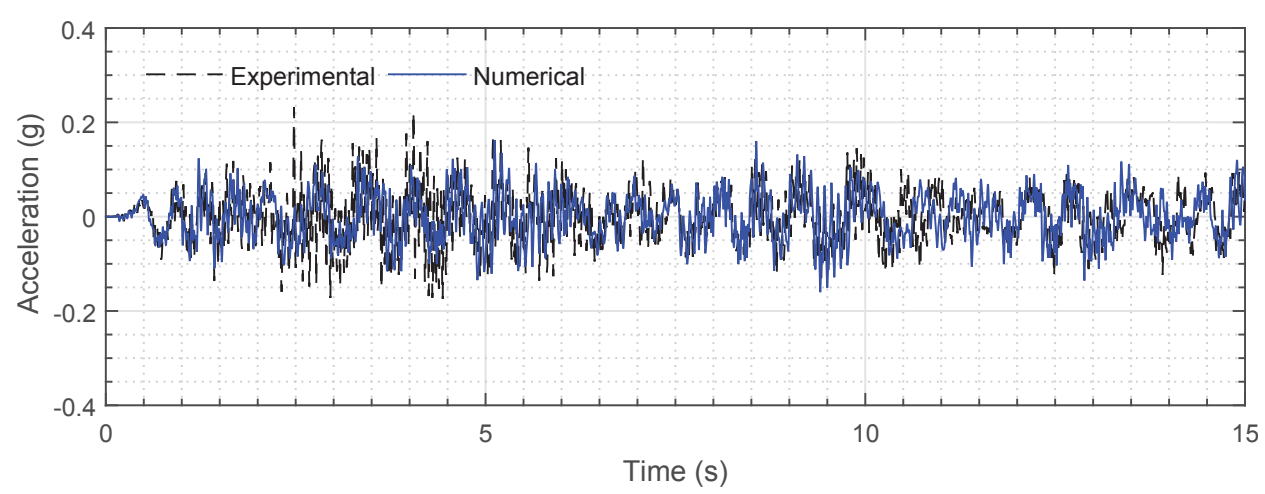

Figure 8: Time series of acceleration response of the $1^{\text {st }}$ story with RB under base excitation.

\section{RB SYSTEM PERFORMANCE UNDER BI-DIRECTIONAL SEISMIC EXCITA- TION}

To evaluate the performance of the RB system in structures under base excitations, simulations using the numerical model previously described were carried out employing three earthquake records and four different RB configurations; thus, comparing the response of the fixedbase building with the response of the system when employing the RB system with different configurations. Accordingly, these results let us conclude about the performance of RB systems as seismic isolators in multicolumn structures.

Earthquake records were selected in order to have: I) excitations that produce high velocities at soil surface, II) excitations with both high frequency and high acceleration and III) moderate excitations [2]; in Table 3 are shown the seismic excitations selected for this work. 


\begin{tabular}{cccccc}
\hline Earthquake & Station & Component & $\begin{array}{c}\text { PGA } \\
(g)\end{array}$ & $\begin{array}{c}\text { PGV } \\
(\mathrm{m} / \mathrm{s})\end{array}$ & $\begin{array}{c}\text { PGD } \\
(\mathrm{m})\end{array}$ \\
\hline \multirow{2}{*}{ Imperial Valley (1979) } & El Centro Array \# 6 & 140 & 0.339 & 0.665 & 0.287 \\
& & 230 & 0.437 & 1.131 & 0.720 \\
Loma Prieta (1989) & \multirow{2}{*}{ Corralitos } & 90 & 0.478 & 0.475 & 0.115 \\
& & 0 & 0.630 & 0.552 & 0.095 \\
Northridge (1994) & \multirow{2}{*}{ Century City } & 90 & 0.256 & 0.214 & 0.060 \\
& & 360 & 0.222 & 0.251 & 0.060 \\
\hline
\end{tabular}

Table 3: Seismic excitations.

It is timely to mention that each of the RB system configuration is determined by a different inclination angle $\theta$ and a different dissipation force $f_{d s}$; i.e., first RB configuration corresponds to $\theta=2.0^{\circ}$, second one corresponds to $\theta=3.5^{\circ}$, third one is given by $\theta=5.0^{\circ}$ and the fourth one is defined by $\theta=5.0^{\circ}+f_{d s}=1.14 \mathrm{~N}$.

To continue, time series responses of displacement, speed and accelerations were obtained, however, only the responses in displacements will be presented. In Figures 9, 10 and 11 are shown the time series of displacement response at the fourth story obtained in the numerical simulations obtained for each of the earthquake records employing the four different RB configurations. Displacements were normalized by the maximum displacement obtained in the simulation of the fixed-based building $u_{\max }$. Due to the fact that only in the weaker direction of the structure the seismic excitation produced noticeable displacements, the parametric analysis was performed only in that direction. By contrast, the seismic excitation, by means of amplitude and frequencies, did not produced noticeable displacements in the stronger direction of the structure.

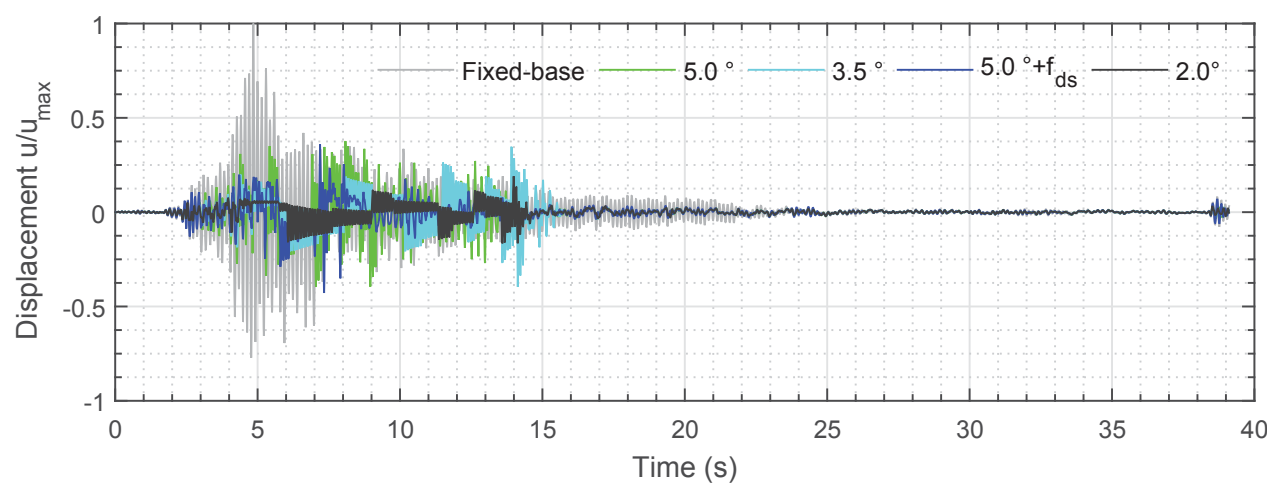

Figure 9: Performance of RB system: Time series of displacement response of the $4^{\text {st }}$ story under base excitation Imperial Valley Earthquake (1979), $u_{\max }=0.0109 \mathrm{~m}$. 


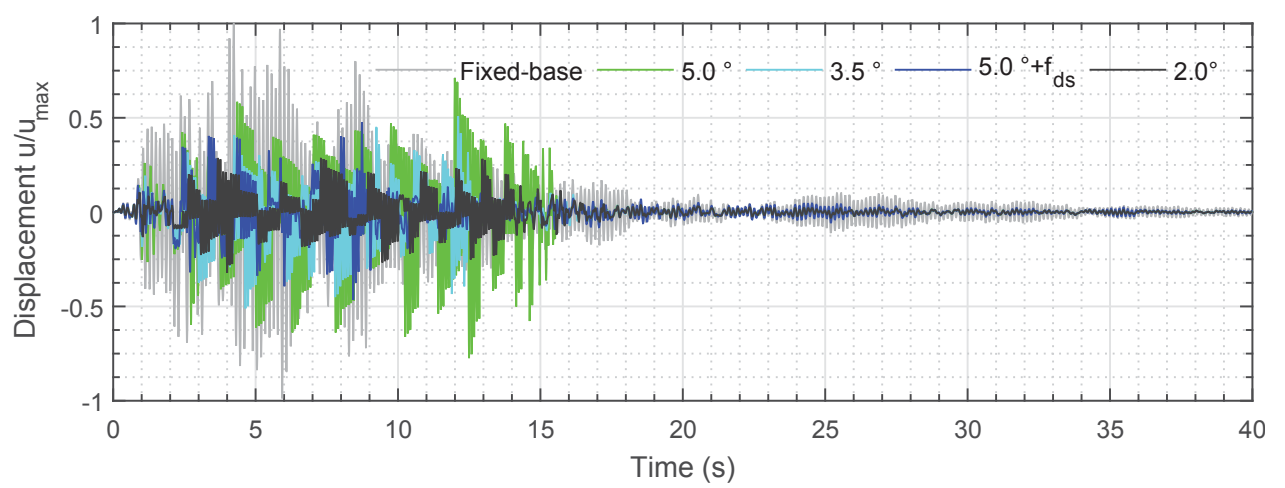

Figure 10: Performance of RB system: Time series of displacement response of the $4^{\text {st }}$ story under base excitation Loma Prieta Earthquake (1989), $u_{\max }=0.0075 \mathrm{~m}$.

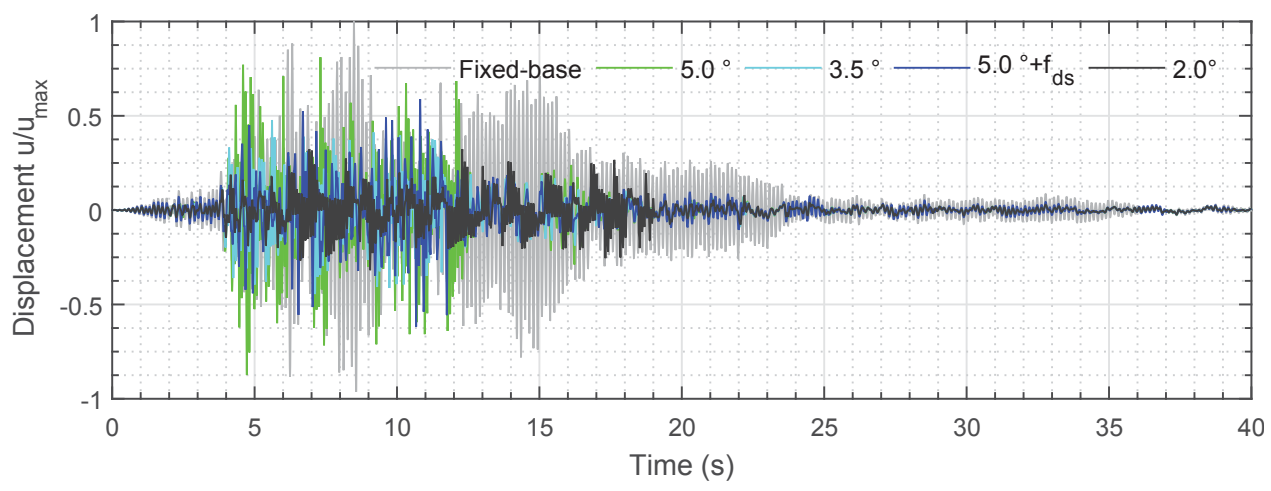

Figure 11: Performance of RB system: Time series of displacement response of the $4^{\text {st }}$ story under base excitation Northridge Earthquake (1994), $u_{\max }=0.0068 \mathrm{~m}$.

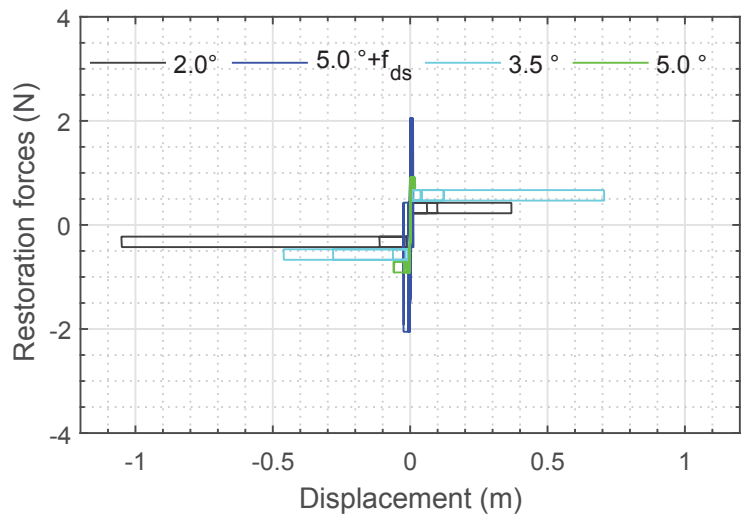

Figure 12: Hysteresis diagrams of isolation devices under base excitation Imperial Valley Earthquake (1979). 


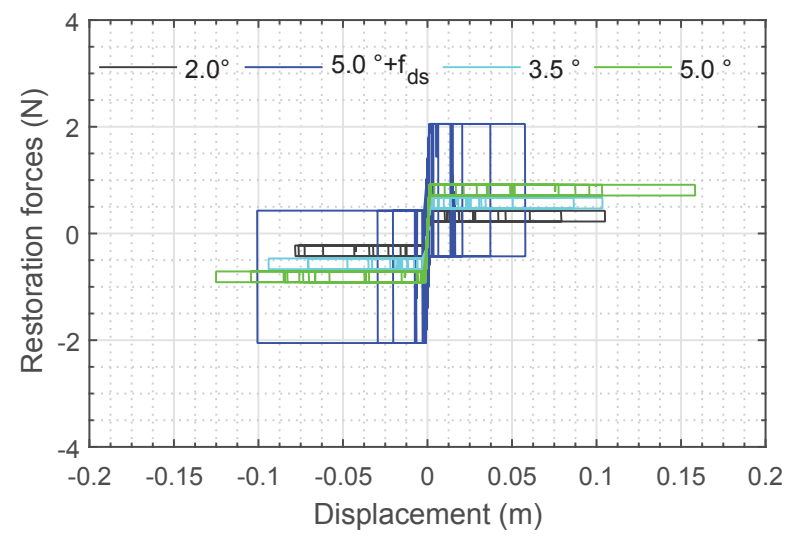

Figure 13: Hysteresis diagrams of isolation devices under base excitation Loma Prieta Earthquake (1989).

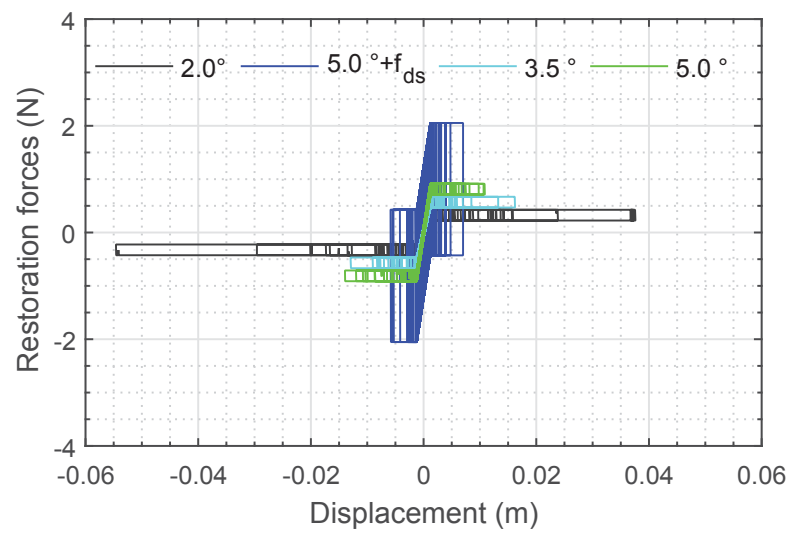

Figure 14: Hysteresis diagrams of isolation devices under base excitation Northridge Earthquake (1994).

Based on the obtained results, it is noticeable that the use of RB system reduce building displacements between $60 \%$ to $80 \%$ for all three seismic excitations compared with the same results obtained in the simulations without RB systems. The seismic building response improve as $\theta$ decreases; however, as $\theta$ decreases, large horizontal displacements result at the base of the structure thus limiting the use of RB systems. To avoid this problem, energy dissipation systems must be implemented to control those large displacements at the base of the structure; thus, improving the performance of the whole seismic isolation system (Fig. 12, 13, 14). It is important to mention that the energy dissipation system have to maintain both the decoupling between the structure and the base and the self-centering capability of the isolator device.

\section{CONCLUSIONS}

The response of a multicolumn structural model employing a Roller Bearing seismic isolation system and the performance of the RB system have been presented. Its performance has been assessed through the simulation of the structural model subjected to seismic excitations. The structural model's response was evaluated by direct comparison between the results of the simulation under fixed-base structure conditions and employing the RB system. It was found that the RB isolation system considerable reduces horizontal displacements relative to the 
base for all earthquake records reviewed in this work. Maximum accelerations also decrease by means of the RB systems compared with those ones computed in the fixed-base structure simulations. In addition, it is important to mention that an energy dissipation system reduced the maximum horizontal displacement at the base of the structure improving the overall performance of the seismic isolation system. Finally, a proper relation between parameters $\theta$ y $f_{d s}$ will give the best performance to the RB system in different seismic excitations.

\section{ACKNOWLEDGMENT}

This research was supported by the Office Vice-Provost for Research at Universidad Militar Nueva Granada under grant number INV-ING-2982, this support is gratefully acknowledged.

\section{References}

[1] R. Jangid, T. Datta, Seismic behavior of base-isolated buildings: A state of the art review, Proceedings of the Institution of Civil Engineers, Structures and Buildings 110 (1995) 186-203.

[2] F. Naeim, J. Kelly, Design of seismic isolated structures: From theory to practice, Wiley \& Sons, New York, USA, 1999.

[3] M. Kunde, R. Jangid, Seismic behavior of isolated bridges: A state of the art review, Electronic Journal of Structural Engineering 3 (2003) 140-170.

[4] P. Harvey, K. Kelly, A review of rolling-type seismic isolation: Historical development and future directions, Engineering Structures 125 (2016) 521-531.

[5] B. Palazzo, L. Petti, Combined control strategy: base isolation and tuned mass damping, ISET Journal of Earthquake Technology 36 (2012) 121-137.

[6] M. Walters, Seismic isolation: The gold standard of seismic protection, in: Structural Performance, Structure Magazine, 2015.

[7] M. Tsai, S. Wu, K. Chang, G. Lee, Shaking table tests of a scaled bridge model with rolling-type seismic isolation bearings, Engineering Structures 29 (2007) 694-702.

[8] V. Matsagar, R. Jangid, Base isolation for seismic retrofitting of structures, Practice periodical on structural design and construction 13 (2008) 175-185.

[9] M. Hosseini, A. Soroor, Using orthogonal pairs of rollers on concave beds (OPRCB) as a base isolation system Part II: Application to multi-story and tall buildings, The Structural Design of Tall and Special Buildings (2010).

[10] M. Erdik, O. Ülker, B. Şadan, C. Tüzün, Seismic isolation code developments and significant applications in Turkey, Soil Dynamics and Earthquake Engineering 115 (2018) 413-437.

[11] K. Ryan, T. Okazaki, C. Coria, E. Sato, T. Sasaki, Response of hybrid isolation system during a shake table experiment of a full-scale isolated building, Earthquake Engineering and Structural Dynamics 47 (2018) 2214- 2232. 
[12] B. Spencer Jr., S. Nagarajaiah, State of the art structural control, Journal of Structural Engineering 129 (2003) 845-856.

[13] G. Lee, Y. Ou, Z. Liag, T. Niu, J. Song, Principles and performance of roller seismic isolation bearings for highway bridges, Technical Report MCEER-07-0019, University at Bufalo, New York, USA, 2007.

[14] N. Ortiz-Cano, C. Magluta, N. Roitman, Numerical and experimental studies of a building with roller seismic isolation bearings, Structural Engineering \& Mechanics 54 (2015) 475-489.

[15] L. Shampine, M. Reichelt, J. Kierzenka, Solving Index-1 DAEs in MATLAB and Simulink, SIAM Review 18 (1999) 538-552. 